\title{
- Doença de Aujeszky Suína: ocorrência e difusão no Estado de São Paulo - Brasil
}

\section{- Aujeszky Disease Swine: occurrence and spreading in São Paulo State - Brazil}

\section{- Enfermedad de Aujeszky Porcina: ocurrencia y difusión en el Estado de São Paulo - Brasil}

* Érico Luiz Krzyzaniak ${ }^{1}$ - CRMV-SP - n 1426 Arnold Frederico Gottschalk ${ }^{2}$ - CRMV-SP $-n^{\circ} 0064$

José Rafael Módolo ${ }^{2}$ - CRMV-SP - $\mathbf{n}^{\circ} 2180$

Carlos Roberto Padovani ${ }^{2}$ - Matemático

Helmuth Kieckhöfer ${ }^{1}$ - CRMV-SP $-n^{\circ} 10452$

Paulo Rogério Saurin Visentini ${ }^{1}$ - CRMV-RS - ${ }^{0} 5394$

1 Professor da UNIMAR, FCA, Marília, SP.

2 Professor do curso de Pós-Graduação da FMVZ - UNESP, Área de Vigilância Sanitária, Botucatu, SP.
- Universidade de Marilia - FCA. Av. Hygino Muzzy, 1001 CEP 17525-902 Marilia-SP Email:ekrzy-ca@unimar.br

\section{RESUMO}

A Doença de Aujeszky é um processo infeccioso de ampla difusão caracterizada por desenvolver infecções latentes e transtornos de ordem reprodutiva em suínos, levando àa prejuízos econômicos substanciais dos agronegócios. Em função das futuras restrições comerciais internacionais pela ocorrência da doença, muitos países vislumbram a possibilidade da adoção de medidas e planos de erradicação da enfermidade. Este trabalho apresenta informações relativas ao sistema de criação, à distribuição geográfica e temporal de episódios, à densidade populacional, trânsito intra-estadual, trânsito interestadual de suínos oriundos dos Estados da Região Sul com destino ao Estado de São Paulo ou com passagem obrigatória pelo terrritório paulista para chegar a outros Estados da Federação, para fins de cria ou abate, e interação desses dados com outros fatores epidemiológicos que possam favorecer a perpetuação da enfermidade.

Palavras-chave: Doença de Aujeszky. Suínos. Trânsito. Ocorrência. Difusão. 


\section{Introdução}

sistema de produção no Estado de São Paulo é caracterizado por suinocultura tipicamente independente, não estando atrelado a sistemas cooperativos e poucos integrados independentes, a exemplo do que ocorre em outros Estados da Federação (PEETZ et al.,1996). A assistência técnica, a educação sanitária, a vigilância sanitária e os programas de saúde são prestadas e desenvolvidos por órgãos oficiais e complementados por empresas com interesses no segmento. Entretanto, o conjunto de esforços desenvolvidos por estas entidades no que se refere a normas gerais de biossegurança, deixa a desejar e não se encontra em patamar aceitável (PEETZ et al., 1996), em conseqüência da insipiência de infra-estrutura sanitária específica para o segmento suinícola. As notificações existentes são obtidas nos atendimentos clínicos efetuados por solicitação dos proprietários; pelos diagnósticos de laboratórios e nos achados de necrópsias e de abatedouros (CRUZ; MARTINS, 1988).

A possibilidade da falta de diagnóstico para várias doenças, hoje consideradas de baixa incidência, é grande, uma vez que o número de laboratórios de diagnóstico, universidades e instituições de pesquisas, envolvidos no diagnóstico regular de doenças, é relativamente pequeno (REIS; REIS, 1995), em relação a população suína brasileira de aproximadamente 28,9 milhões de cabeças, à vasta área territorial do país e às desigualdades tecnológicas verificadas entre as regiões e Estados.

Atualmente, a importação de material genético permite a evolução mais rápida das linhagens, mas há riscos potenciais de natureza sanitária. Na hipótese de importação de animais com status sanitário diferente ou portadores de patologia exótica para o rebanho de destino, a falta de quarentena, complementada com a falta de monitoramento, representa grande risco (REIS; REIS, 1997).

O Estado paulista deixa a desejar em programas sanitários para a pecuária como um todo. $\mathrm{Na}$ suinocultura, alguns criadores procuram, isoladamente, manter seus plantéis livres das enfermidades que julgam de importância, enquanto que outros só se preocupam com a sanidade animal quando da ocorrência da doença, procurando minimizar as perdas econômicas. Em razão de todos esses fatores, a suinocultura paulista tem evoluído lentamente no que se refere aos aspectos sanitários. O agravamento deste quadro é expressivo em função do grande número de criatórios de subsistência, nos quais a preocupação sanitária é praticamente inexistente (PEETZ et al., 1996).
O objetivo deste estudo foi identificar a malha rodoviária utilizada para o trânsito de suínos; levantar a ocorrência temporal e geográfica dos focos da Doença de Aujeszky em suínos e suas implicações sanitárias, correlacionando-as ao diagnóstico de rotina.

\section{Revisão de Literatura}

A Doença de Aujeszky (DA) ou pseudoraiva, é uma moléstia infecciosa, causada por um Herpesvírus, conhecido como vírus da Doença de Aujeszky (VDA). É processo infeccioso de ampla disseminação, ocorrendo nos plantéis suinícolas da grande maioria dos países com suinocultura evoluída, causando sensíveis prejuízos econômicos decorrentes da elevada mortalidade perinatal, dos transtornos ocorridos durante o período de reprodução em fêmeas gestantes, como abortos, repetição de cio e infertilidade, e a perda de peso temporária após o desmame (GUSTAFSON, 1981; ROMERO, 1985; ROMERO et al., 1987). De acordo com Motovsky e Peev (1992), a mortalidade de recém nascidos pode chegar a $66 \%$ até 72 horas após o nascimento em rebanhos infectados. Os nascidos podem apresentar o VDA na sua forma latente, que permanece, possivelmente, durante a vida toda do suíno, sendo liberado, quando é submetido ao estresse. As marrãs são mais susceptíveis no início do que no final da gestação e a infecção transplacentária tem sido a forma básica da transmissão (MOTOVSKY; PEEV, 1992).

Aparentemente, o VDA pode infectar todas as espécies de sangue quente e, quando a dose infectante é elevada, culmina sempre com a morte do hospedeiro (ROMERO, 1985; ROMERO et al., 1987; BLAHA, 1995; KRETZSCHMAR, 1999). O suíno é considerado seu reservatório natural (GUSTAFSON, 1981), com a existência de portadores sadios (SOBESTIANSKY et al., 1993). Segundo Smet, Miielenaere e Pensaert (1989), a situação epizootiológica do VDA é enzooticamente diferente em cada país da Europa Central, os quais vislumbram a possibilidade de futuras restrições comerciais em função da ocorrência da enfermidade. Entretanto o recente desenvolvimento de vacinas deletadas que permitem a diferenciação de animais vacinados e infectados e eliminação de soropositivos, mostra a possibilidade de sucesso de campanha de erradicação. Estudo realizado na Alemanha, por Zimmer e Zimmermann (1997), no período de $1980-95$, mostrou que $8,9 \%$ das mortes de leitões em amamentação, foram provocadas pela DA, 
cuja sazonalidade concentrou-se nos meses de dezembro a março, com $63,6 \%$ de positivos. Esta mesma sazonalidade já havia sido relatada por Christensen et al. (1990), assim como a transmissão por via aérea do vírus, que pode ocorrer num raio de 15 a $40 \mathrm{~km}$, podendo alcançar até $80 \mathrm{~km}$, como constatado em um caso, em temperaturas de $2^{\circ}$ a $5^{\circ} \mathrm{C}$ e elevada umidade relativa. Os episódios coincidiram significativamente com a predominância da direção dos ventos. A ocorrência de epidemias é devida à transmissão do VDA por algumas vias de transmissão, dentre as quais são apontadas como de maior importância o trânsito de animais entre rebanhos, a transmissão do vírus por aerossóis e através de vetores, tais como animais domésticos, roedores, pássaros, roupas e veículos. Segundo estes mesmos autores, independente da via de transmissão, a introdução do VDA em uma população, deve-se considerar uma relação temporal e geográfica da propagação do vírus, observando-se uma maior prevalência de rebanhos afetados em regiões caracterizadas por elevada densidade populacional de suínos, pela proximidade das propriedades, pela direção dos ventos fortes e mobilização constante de suínos. Stegeman e Kimman (1992) relatam que foram identificadas soro-conversões incidentais em marrãs e pouco desenvolvimento de anticorpos em algumas matrizes, em criatórios de suínos, em região de densa população (acima de 1500 suínos por $\mathrm{km}^{2}$ ), com vacinação rotineira e sistemática, nos quais houve a disseminação esporádica de VDA, mas não foi possível se detectar a fonte de infecção. Entretanto, não deve ser descartada a possibilidade da difusão pelo ar ou reativação de vírus latente; isto significa que, para o propósito de erradicação, é inevitável que programas de vacinação sejam implementados em escala ampla. Para Martelli (1996), a implantação de programa de erradicação deve inicialmente passar por sério levantamento dos níveis de prevalência da doença, com adoção de medidas higiênico-sanitárias, despovoamento, repovoamento, isolamento dos neonatos, identificação e eliminação dos infectados e vacinações. Cunningham (1992), ao estudar a erradicação em grandes rebanhos comerciais, obteve bons resultados com o uso de vacinas deletadas e mudanças de manejo e identificou como fatores mais importantes, para a erradicação a movimentação de animais nas unidades de terminação e a densidade animal.

A ocorrência de casos de reagente positivo único, em plantel soronegativo sem histórico de possibilidade de doença, infecção natural ou vacinação, tem criado sérios problemas para as autoridades sanitárias com relação às decisões a serem tomadas em relação ao real estado sanitário da granja, uma vez que este fato possa estar relacionado à especificidade dos testes em uso (OSÓRIO; HOGG; ROCK, 1989).

Embora para Duffy, Morrison e Thawley (1991), a hipótese de introdução externa de VDA não deva ser excluída, por haver a possibilidade de circulação lenta, mas contínua, a reativação de infecções latentes e a disseminação subseqüente parece ser mais plausível no caso de uma difusão persistente.

No programa nacional de erradicação implantado nos Estados Unidos, Leek e Gibbs (1992) alertam para a possibilidade de existência de animais silvestres infectados, dentre eles o javali, e as evidências sugerem que a sintomatologia clínica da doença em adultos selvagens e suínos domésticos são similares.

No Rio Grande do Sul foram coletadas e processadas laboratorialmente 16.305 amostras de soro sangüíneo de suínos, procedentes de 88 municípios, com soronegatividade de todas as amostras testadas e as tentativas de isolamento viral de suínos com sintomatologia clínica sugestiva de DA foram infrutíferas. Em Santa Catarina, foi relatado um surto epidêmico, em 1983, com 100\% de mortalidade de recém nascidos até duas semanas de idade e com $1 \%$ de soropositivos em rebanhos reprodutores. Em 1984, detectaram-se $2 \%$ de soropositivos em plantéis terminadores; em rebanhos reprodutores, em 1985, encontraram-se $0,02 \%$ de soropositivos e, em 1986 , com $0,9 \%$ positivos (ROMERO et al., 1984; ROMERO et al., 1987), e em 1995 (até setembro), foram notificados 12 focos em sete municípios (REIS; REIS, 1995). No Paraná, em 1991, isolou-se VDA de 10 amostras; em 1992, houve quatro isolamentos; em 1993, oito isolamentos; em 1994, dois e, em 1995 (até setembro), 10 isolamentos (REIS; REIS, 1995). De acordo com Araujo (1992) e Reis e Reis (1995), a Zona da Mata, principal região de criadores de suínos de Minas Gerais, revelou baixa prevalência de VDA, o que permitiu considerar a região como, provavelmente, livre da doença. Entretanto, Reis e Reis (1995), ressalvaram que criatórios de fundo de quintal e não assistidos tecnicamente podem constituirse em importantes fontes de difusão. No Distrito Federal, Goiás e Rio de Janeiro não se registraram casos no período de 1990 a 1994. Idêntica situação constatouse no Mato Grosso e Mato Grosso do Sul, no período de 1991 a 1995. No Estado de São Paulo, um levantamento da prevalência da DA, com estratificação das regionais e propriedades, realizado em 1986, pelo Centro de Defesa Sanitária Animal / DDA, em 794 propriedades suinícolas, onde foram coletadas 3.152 
amostras de soro sangüíneo, mostrou $6,17 \%$ das propriedades positivas e $2,41 \%$ de suínos reagentes.

O estudo da distribuição da taxa de prevalência, nas propriedades e nos rebanhos suínos, mostra a doença distribuída em todo o Estado, mas a Regional de Campinas foi a que apresentou a menor taxa de prevalência para as propriedades $(2,02 \%)$, e a menor taxa de prevalência para suínos $(0,76 \%)$ e a Regional de São José dos Campos, com a maior taxa de prevalência, tanto para propriedades $(17,24 \%)$ como para suínos $(9,48 \%)$ (Centro de Defesa Sanitária Animal/DDA, 1986).

\section{Material e Método}

O estudo da movimentação dos suínos e da ocorrência de focos da Doença de Aujeszky abrangeu o período de janeiro de 1990 a dezembro de 1996. Os dados referentes ao trânsito intra-estadual foram analisados através das informações contidas no Boletim Técnico Mensal, elaborados pelos médicos veterinários do Serviço de Defesa Sanitária Animal do Estado de São Paulo que atuam no Núcleo Regional Agrícola de Marília, cujos suínos se destinavam a todos os Núcleos Regionais Agrícolas (Presidente Prudente, Marília, Araçatuba, São José do Rio Preto, Ribeirão Preto, Bauru, Sorocaba, Campinas, Registro e São José dos Campos), contendo as seguintes informações: origem dos animais (Município); período (mês/ano); destino dos suínos; estratificação por Núcleo Regional Agrícola; número das guias de trânsito de animais emitidas e finalidade da movimentação dos suínos (abate, reprodução, recria, acabamento).

Foi observada a mobilização interestadual dos suínos procedentes do Rio Grande do Sul, Paraná e Santa Catarina, com destino ao Estado de São Paulo ou a outras unidades federativas. $\mathrm{O}$ acesso ao território paulista deu-se a partir dos Postos de Fiscalização de Fronteira do Núcleo Regional Agrícola de Marília: Fartu-

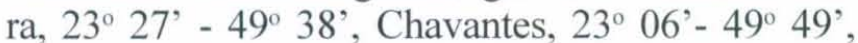
Ourinhos, $22^{\circ} 59^{\prime}-48^{\circ} 58^{\prime}$, Salto Grande, $22^{\circ} 56^{\prime}-49^{\circ}$ 59' e Florínea, $22^{\circ} 57^{\prime}-50^{\circ} 50^{\prime}$ ) e os dados da inspeção foram anotados em relatórios diários específicos e contemplavam as seguintes informações: Serviço de Defesa Agropecuária; Município; posto de fronteira; espécie animal; data; número da guia de trânsito; número da inspeção; procedência (Município/Estado); destino (Município/Estado); número de suínos e finalidade da movimentação.

Pela origem e destino dos animais foram identificadas as rodovias pelas quais ocorreram os deslocamentos. Os diagnósticos foram realizados pelo Ins- tituto Biológico de São Paulo, a partir do qual se determinou a localização das propriedades-focos, de acordo com a latitude sul e longitude oeste, tendo como referência a sede do Município de ocorrência do episódio. A caracterização epidemiológica abordou as informações referentes aos criatórios nos diferentes Núcleos Regionais Agrícolas, com enfoque na densidade da população suína; no número de criatórios existentes; na freqüência da enfermidade, no número de suínos em trânsito e na estacionalidade da doença. A taxa de rebanhos afetados foi determinada por mil propriedades. O trânsito dos suínos e das guias de trânsito de animais emitidas, o destino, a ocorrência da doença e dos fo$\cos$, foram descritos pela freqüência (relativa percentual, absoluta e acumulada), e o estudo estatístico das distribuições sistemáticas ou casuais foi realizada pelo Teste do Quiquadrado com as conclusões discutidas em nível de 5\% de significância.

\section{Resultados e Discussão}

A Figura 1 apresenta o mapa do Estado de São Paulo, destacando a disposição geográfica do Núcleo Regional Agrícola de Marilia, sede administrativa da $11^{\text {a }}$ Região, em relação às outras regionais do Estado, e identificando os Postos de Fiscalização de Fronteira, com as respectivas rodovias: Florínea, SP-333; Ourinhos, BR-153; Chavantes, SP-276; Fartura, SP249 e Salto Grande, Perímetro urbano, pelas quais ocorreu o acesso dos animais ao Estado. Os dados levantados permitiram enfocar a mobilização interestadual dos suínos, que necessariamente precisaram transitar pelo território paulista, para chegar ao seu destino.

Com relação à mobilização mensal de suínos, procedentes da Região Sul com destino a outros Estados da Federação, discriminada no Quadro 1, foi emitido um total de 3.820 guias de trânsito animal, para 651.927 suínos destinados ao abate, e 1.035 guias de trânsito animal, para 45.963 suínos destinados para cria. Estes suínos tiveram como destino os Estados de Alagoas, Bahia, Ceará, Distrito Federal, Espirito Santo, Goiás, Minas Gerais, Mato Grosso, Mato Grosso do Sul, Pará, Pernambuco, Rio de Janeiro, Rio Grande do Norte e Tocantins.

Por outro lado, os animais de mesma origem e com destino ao Estado de São Paulo, totalizaram a emissão de 8.730 guias de trânsito animal, para 1.484.241 suínos para abate e 1.413 guias de trânsito animal, para 128.170 suínos para cria. O total de suínos em trânsito no Estado de São Paulo foi de 2.310.301, com média anual de 330.043 animais re- 
presentando aproximadamente $25 \%$ da população total do Estado. Desse total, 128.170 animais foram destinados a São Paulo para cria, perfazendo a média anual de 18.310 animais, equivalente a $1,41 \%$ da população suína do Estado de São Paulo, os quais foram incorporados ao rebanho paulista como reprodutores ou para terminação. Consequentemente, estes animais, talvez portadores inaparentes, sem imunização, representaram possíveis fontes de infecção, levando a riscos sanitários.

O volume de aporte, diferenciado para cada unidade executora (Quadro 2), é fa-

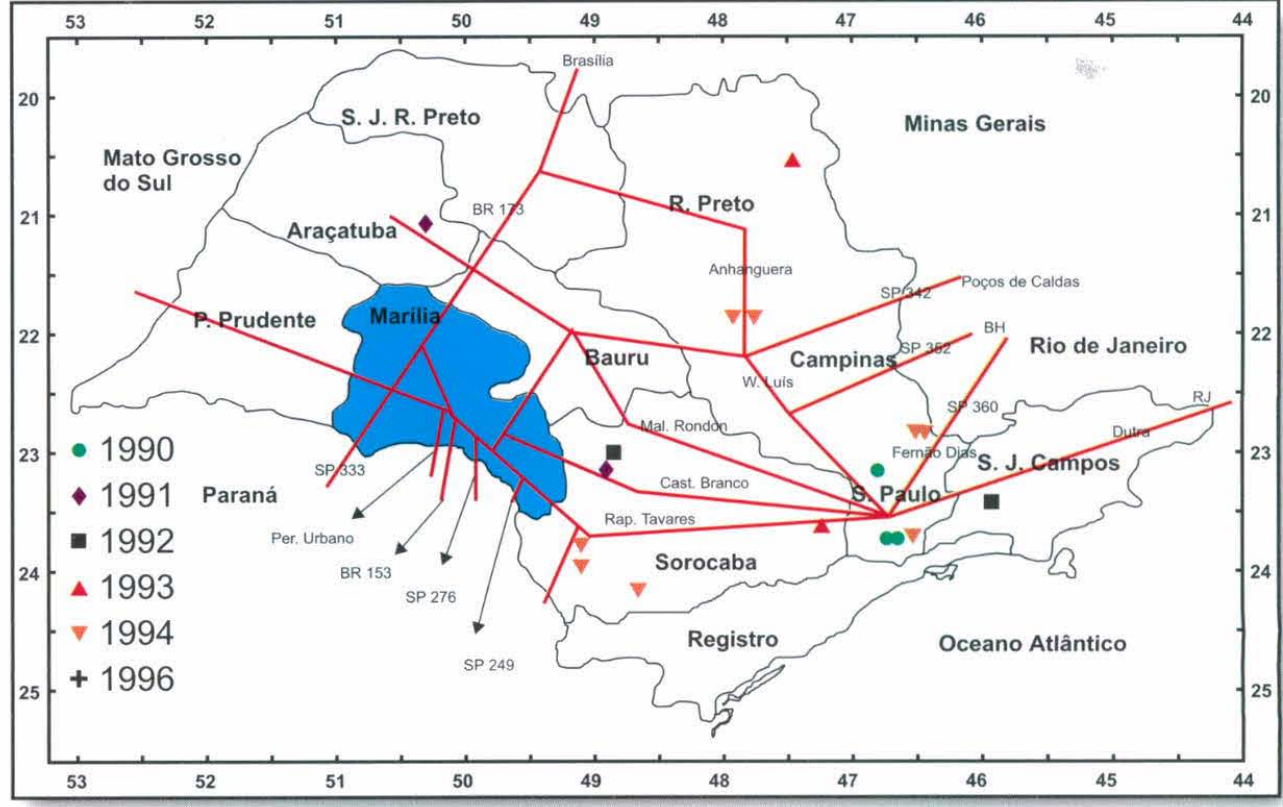

Figura 1 - Mapa do Estado de São Paulo, com destaque ao Núcleo Regional Agrícola de Marília, localização dos Postos Fiscais de Fronteira, malha rodoviária e distribuição espacial dos focos. vorecido pela localização da unidade de controle de trânsito animal, pelo tipo de rodovia de acesso e pelas facilidades de deslocamentos às principais vias que levam a estas unidades. Portanto, as cinco unidades do controle de trânsito são servidas por malha rodoviária comum. Algumas estradas/rodovias apresentam boa infra-estrutura, proporcionando melho-

\begin{tabular}{|l|c|c|c|c|c|c||}
\hline \multicolumn{3}{|c|}{ TRÂNSITO INTRA-ESTADUAL } & \multicolumn{3}{c|}{ TRÂNSITO INTERESTADUAL } \\
\hline \multicolumn{2}{|c|}{} & \multicolumn{2}{|c|}{ Região Sul/São Paulo } & \multicolumn{2}{|c|}{$\begin{array}{c}\text { Região Sul/Outros } \\
\text { Estados }\end{array}$} \\
\hline Mês & $\begin{array}{c}\text { Animais } \\
\text { abate }\end{array}$ & $\begin{array}{c}\text { Animais } \\
\text { cria }\end{array}$ & $\begin{array}{c}\text { Animais } \\
\text { abate }\end{array}$ & $\begin{array}{c}\text { Animais } \\
\text { cria }\end{array}$ & $\begin{array}{c}\text { Animais } \\
\text { abate }\end{array}$ & $\begin{array}{c}\text { Animais } \\
\text { cria }\end{array}$ \\
\hline Jan. & 4.828 & 0 & 160.807 & 11.646 & 62.436 & 3.315 \\
\hline Fev. & 4.701 & 160 & 95.676 & 7.158 & 28.126 & 2.785 \\
\hline Mar. & 9.668 & 107 & 80.819 & 7.734 & 31.228 & 3.156 \\
\hline Abr. & 8.095 & 18 & 107.470 & 8.862 & 30.821 & 2.140 \\
\hline Maio & 10.993 & 3 & 115.369 & 8.110 & 45.723 & 3.467 \\
\hline Jun. & 9.498 & 35 & 118.167 & 9.748 & 50.754 & 5.162 \\
\hline Jul. & 7.881 & 0 & 139.418 & 7.600 & 58.962 & 2.186 \\
\hline Ago. & 7.477 & 15 & 124.170 & 10.973 & 68.735 & 2.960 \\
\hline Set. & 7.463 & 8 & 140.456 & 10.411 & 63.020 & 7.224 \\
\hline Out. & 7.933 & 150 & 110991 & 11.616 & 65.807 & 5.482 \\
\hline Nov. & 6.989 & 18 & 122.574 & 20.135 & 74.602 & 3.632 \\
\hline Dez. & 8.704 & 0 & 168.274 & 14.177 & 71.713 & 4.454 \\
\hline Total & 94.230 & 514 & 1.484 .241 & 128.170 & 651.927 & 45.963 \\
\hline
\end{tabular}

Quadro 1 - Mobilização mensal de suinos da Região de Marilia, com destino às Regiões Administrativas do Estado e $\mathrm{n}^{\circ}$ de suínos procedentes da Região Sul com destino ao Estado de São Paulo e a outros Estados da Federação, no período de janeiro de 1990 a dezembro de 1996. 
res condições de deslocamentos, enquanto outras, consideradas secundárias ou vicinais, com topografia acidentada, sinuosas e deficientes em prestação de assistência mecânica em possíveis emergências, só podem ser utilizadas em situações especiais.

As granjas produtoras de suínos da Região Sul tem sua localização geográfica predominante nas regiões oeste dos Estados de Santa Catarina e Paraná e noroeste do Rio Grande do Sul. Tal fato representa fator determinante das rotas e parecem limitar e direcionar, de forma seletiva, a opção para o transporte de suínos pelas rodovias que favorecem os deslocamentos, proporcionando maior rapidez, aumento da capacidade de carga e minimizando custos de transporte, como observado pelo grande volume de trânsito de suínos nas unidades de Florínea, Fartura e Ourinhos.

\begin{tabular}{|l|c|c|c|c|c|c|c|c|}
\hline ORIGEM/DESTINO & \multicolumn{3}{|c|}{ REGIÃO SUL/OUTROS ESTADOS } & \multicolumn{3}{c|}{ REGIÃO SUL/REGIÕES PAULISTAS } \\
\hline & \multicolumn{2}{|c|}{ Abate } & \multicolumn{2}{|c|}{ Cria } & \multicolumn{2}{|c|}{ Abate } & Cria \\
\hline Postos de Fiscalização & Suínos & $\%$ & Suínos & $\%$ & Suínos & $\%$ & Suinos & $\%$ \\
\hline Fartura & 181.104 & 27,8 & 15.167 & 33,0 & 345.219 & 23,2 & 36.669 & 28,6 \\
\hline Chavantes & 0 & 0,0 & 0 & 0,0 & 24 & 0,0 & 5 & 0,0 \\
\hline Ourinhos & 122.472 & 18,8 & 13.234 & 28,8 & 183.547 & 12,4 & 15.491 & 12,1 \\
\hline Salto Grande & 0 & 0,0 & 0 & 0,0 & 14 & 0,0 & 2 & 0,0 \\
\hline Florínea & 348.351 & 53,4 & 17.562 & 38,2 & 955.437 & 64,4 & 76.003 & 59,3 \\
\hline Total & 651.927 & 100 & 45.963 & 100 & 1.484 .241 & 100 & 128.170 & 100 \\
\hline
\end{tabular}

Quadro 2 - Fluxo interestadual da mobilização de suinos por Posto Fixo de Fiscalização de Fronteira.

A preferência para os deslocamentos no Estado de São Paulo, incide nas rodovias Raposo Tavares e Castelo Branco, cujo fluxo de direcionamento concentra o trânsito para a região de Campinas, mais especificamente para a Grande São Paulo, onde estão localizadas algumas das principais indústrias de abate de suínos. A BR-153, direciona a mobilização para a região de São José do Rio Preto, onde se concentra outro centro industrial suinícola. O trânsito dos animais destinados a outros Estados da Federação, distribui-se para diversas rodovias como: Marechal Rondon, Anhangüera, Washington Luís, SP-342, SP-352, Fernão Dias e Dutra (Figura 2) por apresentarem melhores condições de rolamento e toda infra-estrutura necessária a deslocamentos rápidos e seguros, condições estas indispensáveis e necessárias para a mobilização, que, se realizada em condições inadequadas, pode levar a graves prejuízos, como a perda de peso, desconforto, aumento do estresse, com o favorecimento da eliminação e difusão do agente etiológico para os animais de granjas localizadas em áreas próximas as rodovias.

Com relação ao trânsito intra-estadual (Quadro 1), foi emitido um total de 1.303 guias de trânsito para 94.230 suínos destinados ao abate e 18 guias de trânsito para 514 suínos para cria. Esse trânsito foi avaliado a partir de suínos oriundos do Núcleo Regional Agrícola de Marília e destinados para os Núcleos Regionais de: Araçatuba, Bauru, Campinas, Marília, Presidente Prudente, Registro, Ribeirão Preto, Sorocaba, São José dos Campos e São José do Rio Preto, cuja fiscalização é realizada nas rodovias por equipes volantes compostas de auxiliares técnicos com a presença ou não de médico veterinário, mas sempre acompanhadas pela polícia rodoviária e executada de acordo com programação mensal pré-estabelecida. O desempenho da fiscalização parece ser deficitário, quando avaliado frente a uma população suína de 107.665 animais, do Núcleo Regional Agrícola de Marília. Os números representam mobilização anual média de aproximadamente 13.534 suínos, correspondentes a $12,57 \%$ do efetivo suíno regional. Este percentual, relativamente baixo se comparado com a taxa de desfrute esperada em qualquer sistema de produção de suínos, e permite consolidar a hipótese da possibilidade da mobilização de animáis sem a necessária autorização para o trânsito. Em eventual ocorrência de episódios mórbidos, seguramente seria dificultada a ação dos ser- 
viços de defesa sanitária animal e comprometidos os resultados finais de controle ou erradicação de foco.

Nos meses de janeiro, julho e dezembro, não foi constatada emissão de atestados para cria e observou-se menor número de emissões de autorização de trânsito de suínos para abate nos meses de janeiro e fevereiro. Sugestivamente, corresponde aos meses em que maior número de funcionários encontra-se em férias regulamentares e as fiscalização volante é feitas em menor quantidade. Entretanto, há aumento dos deslocamentos no período de março a junho $(40,60 \%)$ para abate e $81,12 \%$ dos suínos destinados à cria, este com aumento de volume de trânsito nos meses de fevereiro, março e outubro, não caracterizando sazonalidade para esta modalidade de deslocamento.

A distribuição de freqüência do número de relatos do trânsito apresentado nas três modalidades estudadas, não foi homogênea e o trânsito, a partir do Núcleo Regional Agrícola de Marília para os demais Núcleos Regionais Agrícolas do Estado, foi quantitativamente inferior e estatisticamente significativo $(\mathrm{P}<0,01)$. Contudo, a distribuição dos relatos no período mostrou-se semelhante no quadriênio inicial, enquanto no triênio final do estudo, ocorreu a majoração dos valores anuais, com discreto aumento, mas crescente, do número de suínos em trânsito $(\mathrm{P}<0,01)$, possivelmente explicado pela implantação da nova sistemática de controle de trânsito e implementação de carne suína na dieta dos consumidores.

A doença encontra-se distribuída em universo de 18 (2,79\%), dos 645 municípios paulistas, sugerindo que a enfermidade não apresenta distribuição homogênea no Estado - o que contraria as conclusões do levantamento de prevalência realizado em 1986 - e está disseminada em regiões onde a exploração suinícola se faz presente em maior intensidade. A distribuição geográfica e a freqüência dos focos da doença em rebanhos naturalmente afetados, por Núcleo Regional Agrícola (Figura 2), mostraram predominante incidência nas áreas de maior concentração de criatórios, onde há maior densidade de suínos, de animais por propriedade e onde há concentração do trânsito de convergência. Estes fatores favorecem a difusão e persistência da enfermidade, proporcionando oportunidade para maior número de ocorrências, observadas nos Núcleos Regionais Agrícolas de Campinas onde se concentra $31,3 \%$ da população suína do Estado, $6(30,0 \%)$ focos e 17,8 suínos $/ \mathrm{km}^{2}$; Sorocaba, com $18,2 \%$ da população, $6(30,0 \%)$ focos e 5,9 suínos $/ \mathrm{km}^{2}$; Ribeirão Preto, com 13,4\% da população, $3(15,0 \%)$ focos e 4,7 suínos $/ \mathrm{km}^{2}$; Marília, com $8,3 \%$ da população, 3
(15,0\%) focos e 5,6 suínos $/ \mathrm{km}^{2}$; Araçatuba, com 2,7\% da população, $1(5,0 \%)$ foco e 1,9 suínos $/ \mathrm{km}^{2}$ e São José dos Campos, com 3,7\% da população, 1 (5,0\%) foco e 3,4 suínos $/ \mathrm{km}^{2}$. Nos Núcleos Regionais Agrícolas de Bauru, com 5,5\% da população e 4,4 suínos/ $\mathrm{km}^{2}$; Presidente Prudente, com $3,5 \%$ da população e 1,8 suínos $/ \mathrm{km}^{2}$; Registro, com $1,7 \%$ da população e 0,8 suínos $/ \mathrm{km}^{2}$ e São José do Rio Preto, com 11,4\% da população e 5,5 suínos $/ \mathrm{km}^{2}$ não registraram diagnóstico para a DA no período $(\mathrm{P}<0,01)$.

A análise da distribuição da freqüência anual dos 20 focos diagnosticados em rebanhos naturalmente afetados, mostrou maior ocorrência no ano de 1994, com 8 (40,0\%) focos; seguido de 1990 e 1993, com 3 $(15,0 \%)$ focos anuais; 1991,1992 e 1996 com 2 $(10,0 \%)$ focos anuais e 1995 com nenhum diagnóstico $(\mathrm{P}<0,01)$ (Figura 3). Esse fato possivelmente explicado pelo auto controle da enfermidade após o período de surto e por se adotar medidas saneadoras. A média anual de focos diagnosticados, no período foi de 2,85; no ano de 1994 verificou-se maior ocorrência de episódios, enquanto que 1995 não se confirmou nenhum diagnóstico. Os diagnósticos anuais de focos apresentam-se de forma continuada, havendo a intercorrência de alternância de período de maior e menor incidência, nos anos de 1994 e 1995 , respectivamente. A distribuição mensal da freqüência dos focos mostrou: agosto com 4 (20\%) focos; março, junho e setembro com 3 (15\%) focos mensais; julho com $2(10 \%)$ focos; janeiro, abril, maio, outubro e novembro com $1(5, \%)$ foco mensal e fevereiro e dezembro não apresentaram ocorrência $(\mathrm{P}>0,05)$. A exceção do mês de março, a maior incidência verificou-se no período de junho a setembro com 12 (60\%) focos, sugestivamente correspondente ao inverno, estação com temperatura mais baixa e poucas precipitações pluviométricas, concordando com os achados descritos por Christensen et al. (1990), Scheidt et al. (1992) e Zimmer e Zimmermann (1997) (Figura 4).

De acordo com Trevisol et al. (1995), no Rio Grande do Sul, todos os testes sorológicos e pesquisas laboratoriais foram negativos para a DA, o que pode ser explicado pelo transporte de suínos no sentido sulnorte, de modo a ser reduzida a possibilidade de introdução de animais infectados, implicando no baixo risco pelo contágio indireto. Ao contrário, o Estado de São Paulo parece oferecer condições que favorecem a difusão da doença, pelo intenso trânsito de suínos procedentes da Região Sul, mais especificamente dos Estados do Paraná e Santa Catarina, com possibilidade de deslocamentos de suínos portadores inaparentes em sua 
forma de infecção latente de acordo com estudos de Romero et al. (1984); Romero et al. (1987); Dambros et al. (1995); Reis e Reis (1995) e Norman et al. (1996).

A distribuição geográfica dos focos de DA (Figura 1) demonstra nítido padrão de obediência à disposição das rodovias, concordando com relatos de difusão de Duffy, Orrison e Thawley (1991); Mortensen e Christensen (1992) e Stegeman e Kimman (1992). Esses mesmos autores, asseguram que para a disseminação da doença, devem ser consideradas as diversas formas de transmissão e meios de difusão pelas quais o agente etiológico pode se fazer presente nas propriedades. A situação epidemiológica em que se encontra

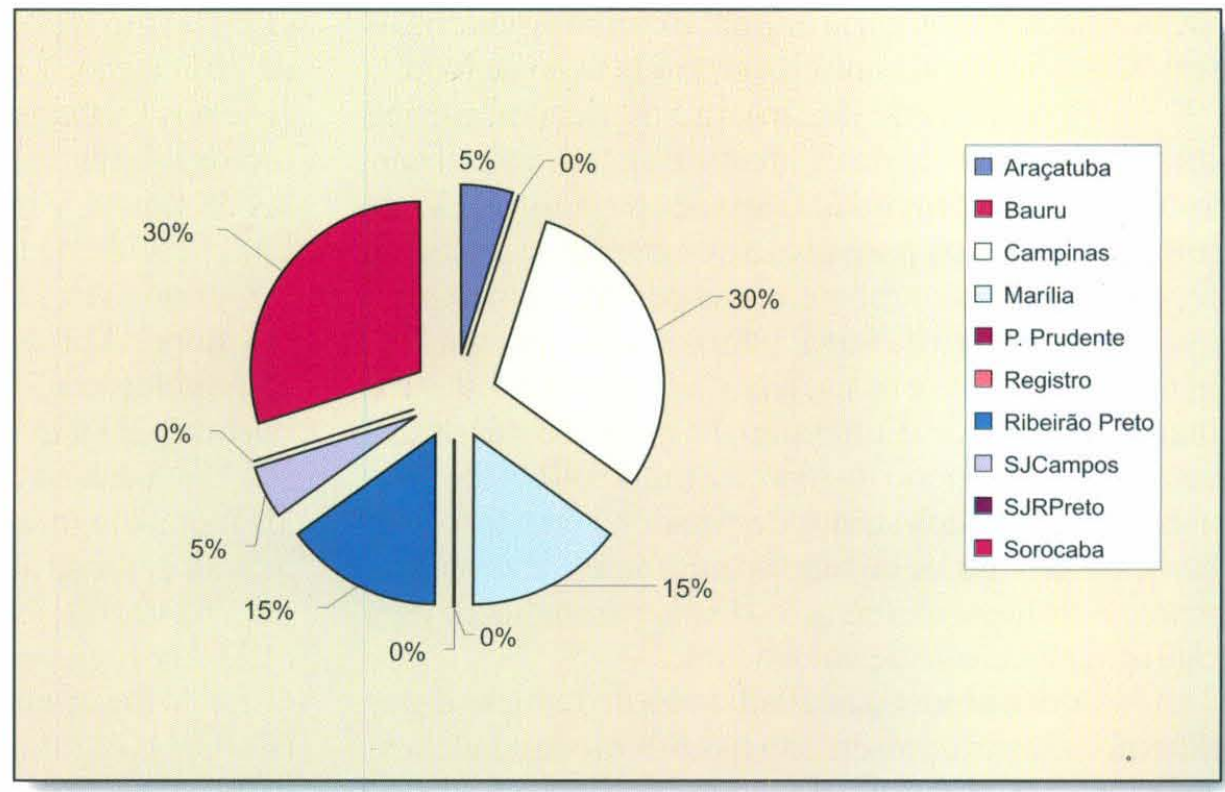

Fonte: Centro de Defesa Sanitaria Animal, DDA/CDA/SAA.

Figura 2 - Distribuição dos focos da Doença de Aujeszky por Núcleo Regional Agrícola, no período de 1990 a 1996. o Estado Paulista é confirmada pelos relatos de Marsh, Damrongwatanapokin e Larntz (1991), que demonstram, pelos resultados obtidos, que a sobrevivência do VDA e sua disseminação são favorecidos pela via aerógena, proximidade de rebanhos com ciclo completo, imunizações restritas a algumas propriedades e elevada densidade populacional. Todavia, a transmissão do vírus de propriedade a propriedade possivelmente exerça papel de menor importância, uma vez que a densidade populacional do Estado encontra-se aquém das descritas. Tais fatos, também relatados por Mortensen e Christensen (1992), asseguram ser necessária uma densidade elevada, isto é, acima de 1.500 suínos por $\mathrm{km}^{2}$, para o favorecimento de difusão do vírus entre propriedades. Estes fatos talvez expliquem os baixos índices de soropositivos, encontrados no levantamento da soro prevalência realizado pelo Centro de Defesa Sanitária Animal/DDA (1986). Também explicaria o reduzido número de focos detectados no período de 1990-96, com a possibilidade do agente etiológico circulante manter-se na propriedade. Estas observações parecem concordar com Kerby et al. (1997), que relata que a DA tende a ser mais prevalente em rebanhos maiores, com mais de 400 matri- zes, por apresentar grande número de neonatos, considerada como a faixa etária mais susceptível. Houben et al. (1993) fazem referência à importância da difusão pelo trânsito, baseados em simulações computadorizadas, pelo fato da circulação de vírus em rebanhos infectados ser processo dinâmico do qual depende a evolução da infecção. Entretanto, no Estado de São Paulo, não é usual o monitoramento sorológico de rebanhos para acompanhamento da situação sanitária, e Duffy, Morrison e Thawley (1991), alertam que não é necessária a reintrodução ou transmissão, uma vez que o VDA pode se difundir a partir de suínos latentemente infectados, quando submetidos a situações

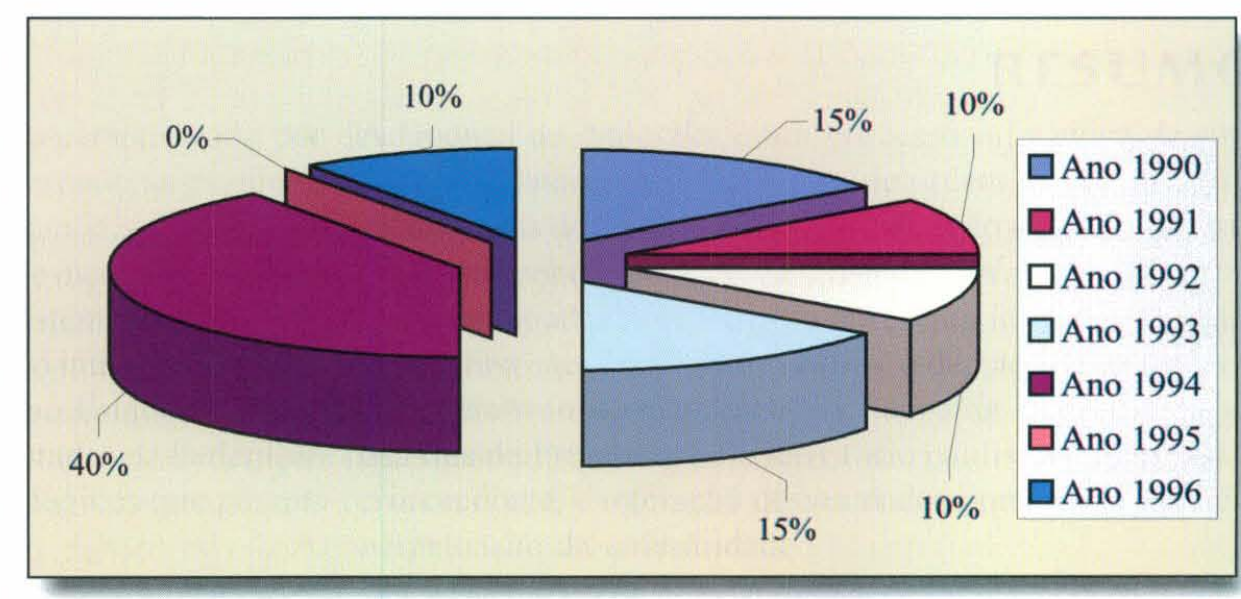

Fonte: Centro de Defesa Sanitária Animal, DDA/CDA/SAA

Figura 3 - Distribuição anual dos focos. 


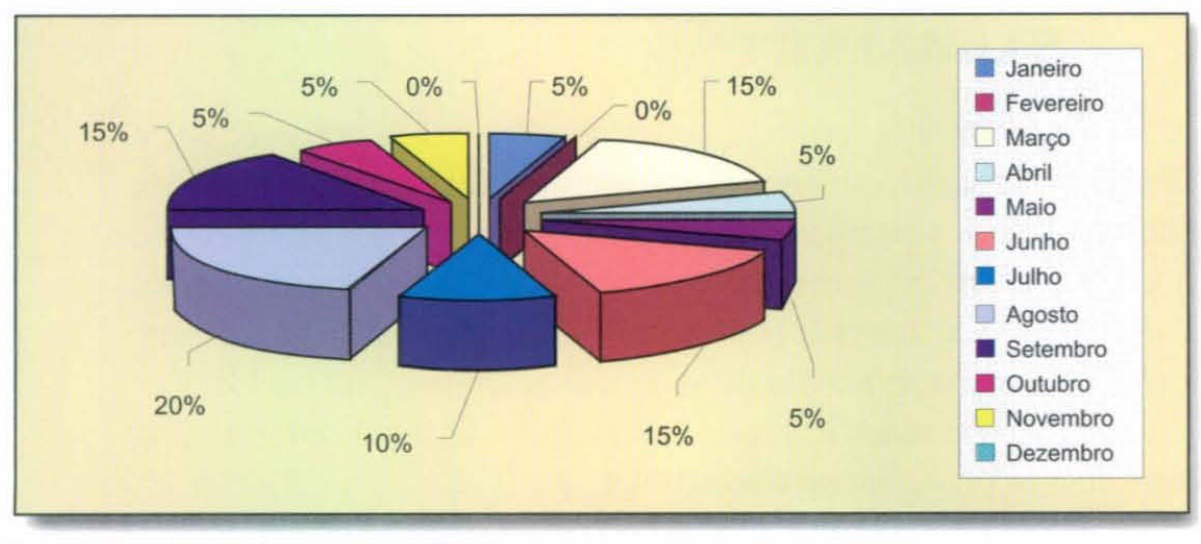

Fonte: Centro de Defesa Sanitaria Animal, DDA/CDA/SAA.

Figura 4 - Distribuição mensal dos focos da Doença de Aujeszky, no periodo de 1990 a 1996

\section{Conclusões}

Para as condições em que foi realizado este presente estudo, ficou evidenciado que a doença está restrita a poucos Municípios, contrariando as conclusões da soroprevalência realizada em 1986, o que mostra a necessidade de melhor acompanhamento e monitoramento dos criatórios, com incremento dos diagnósticos sorológicos, de forma a retratar a real situação da enfermidade. Constatou-se maior ocorrência de focos

de estresse. Por outro lado, as citações nacionais de Romero et al. (1984), Romero et al. (1987) e Reis e Reis (1995) mostram isolamentos e diagnósticos laboratoriais nos Estados de Santa Catarina e Paraná em níveis aparentemente baixos, para rebanhos daqueles Estados. Entretanto, existe a possibilidade do trânsito de suínos portadores inaparentes e sua incorporação aos rebanhos paulistas.

Aspecto atual que merece atenção no Estado de São Paulo é o incremento de criatórios de espécies selvagens ou exóticas, dentre eles o javali. A possibilidade do envolvimento desta espécie na cadeia epidemiológica não deve ser descartada, de acordo com relatos de Leek e Gibbs (1992).

As variações dos valores observados para o índice epidemiológico da Taxa de Rebanhos Afetados, anualmente, referentes aos episódios onde se verificou a incidência natural da enfermidade, por mil propriedades no período estudado, no Estado de São Paulo, com base no diagnóstico laboratorial foi de: 1990 - 0,07; 1991 - 0,04; 1992 - 0,04; 1993 - 0,07; 1994 - 0,19; $1995-0,00$ e $1996-0,04$. nos Núcleos Regionais Agrícolas de Campinas, Sorocaba, Ribeirão Preto e Marília, onde se concentram as granjas e há maior densidade populacional. A distribuição geográfica dos focos obedece a disposição da malha rodoviária, usada para os deslocamentos dos suínos e a incidência matem-se mais elevada no período correspondente aos meses de junho a setembro, período em que prevalecem temperaturas mais baixas. A solução para os deslocamentos irregulares, pode estar na implantação de sistema de informatização através de terminais computadorizados, com dados disponibilizados permanentemente, inclusive em feriados e finais de semana. O sistema contemplaria, além das necessárias informações cadastrais, as áreas de foco e perifocos, com bloqueios automáticos das emissões da autorização para deslocamentos de suínos. Essa sistemática, certamente favoreceria o aumento do número de emissões de autorização de trânsito, com a formação de banco de dados dinâmico e atualizável, e traria como benefício o melhor controle sanitário, abrindo possibilidades mais concretas para rastreamentos, beneficiando o sistema de vigilância sanitária como um todo. 


\section{SUMMARY}

Aujeszky disease is an infeccions one with wide spreading characterized by development of latent infeccions and reprodutive problems in swine herd resulting large economical damage in agribusiness. A lot of countries descry possible attitudes for erradication plans of disease worried about future international marketing restritions. This work presents informations related to herd management method, spacial and temporal distribution of occurrence, population density, intrastate and interstate transit of animals coming from South Region to São Paulo state and other ones, for suckling or slaughter, that need to cross over São Paulo to reach its receiver. It's discussed too its intertwining with other epidemiological factors that may collaborate disease endless.

Key words: Aujeszky disease. Swine. Occurrence. Spreading. Transit.

\section{RESUMEN}

La Enfermedad de Aujeszky es un proceso infeccioso ampliamente difundido, caracterizado por desarrollar infecciones latentes y trastornos de orden reproductivo en porcinos, produciendo pérdidas económicas substanciales en los agronegocios. Muchos países vislumbran la posibilidad de adoptar medidas y planes de erradicación de la enfermedad, teniendo en cuenta las futuras restricciones comerciales internacionales, en función de la ocurrencia de la enfermedad. Este trabajo presenta informaciones relativas al sistema de cría, distribución espacial y temporal de episodios, la densidad poblacional, el tránsito intraprovincial y el tránsito interprovincial de porcinos provenientes de los Estados de la Región Sur con destino al Estado de São Paulo o a otros Estados de la Federación para cría o faena, que necesitan transitar por el territorio paulista para llegar a su destino, y su interacción con otros factores epidemiológicos que puedan favorecer la perpetuación de la enfermedad.

Palabras clave: Enfermedad de Aujeszky. Porcinos. Tránsito. Ocurrencia. Difusión.

\section{REFERÊECIAS}

ARAUJO, R. F. Prevalência e avaliação de estratégia de controle da doença de Aujeszky em suínos na Zona da Mata, Minas Gerais, Brasil (1991). Arquivo Brasileiro de Medicina Veterinária e Zootecnia v. 44, n. 5, p. 445-447, 1992.

BLAHA, T. Epidemiologia especial veterinaria. Zaragoza: Acribia. 1995. p. 110-117.

CENTRO DE DEFESA SANITÁRIA ANIMAL/DDA. Diagnóstico de situação da doença de Aujeszky no Estado de São Paulo. Documento técnico, CATI, n. 66, 1986. 76 p. Mimeografado.
CHRISTENSEN, L. et al. Evidence of long distance airbone transmission of Aujeszky's disease (pseudorabies) virus. The Veterinary Record, v. 127, n. 19, p. 471-474, 1990.

CRUZ, R. M. F.; MARTINS, F. A. Alguns aspectos de sanidade da população suína no Estado de São Paulo: Diagnóstico de situação (1986/1987/1988) - Comentários e Sugestões. Campinas, SP: Departamento de Defesa Agropecuária. Centro de Defesa Sanitária Animal, 1988. 45 p. Mimeografado.

CUNNINGHAM, J. M. Aujeszky's Disease Field Eradication Experiences. Smithkline Beecham Animal Health, Exton, 1992. $1 \mathrm{p}$. 
DUFFY, S. J.; MORRISON, R. B.; THAWLEY, D. G. Factors associated with spread of pseudorabies virus among breeding swine in quarantined herds. Journal of the American Veterinary Medical Association, v. 199, n. 1, p. 66-70, 1991.

GUSTAFSON, D. P. Pseudorabies. In: LEMAN, A. D.; GLOCK, R. D.; MENGELING, W. L.; PENNY, R. H.; SCHOLL, B. Diseases of swine. 5. ed. Ames: Iowa States University Press, 1981. p. 209-223.

KERBY, P. J. et al. First diagnosis of Aujeszky's disease in Bolivia. The Pig Journal-Refereed Section, v. 38, p. 37-39, 1997.

KRETZSCHMAR, C. Doença de Aujeszky. In: BEER, J. Doenças infecciosas em animais domésticos. São Paulo: Roca, 1999. p. 295-305.

LEEK, M. L.; GIBBS, E. P. J. Aujeszky's disease virus infections in wild swine en the USA. In: CONGRESS INTERNATIONALPIG VETERINAY SOCIETTY, 12., 1992, Holanda. Proceeding... p. 86.

MARSH, W. E.; DAMRONGWATANAPOKIN, T.; LARNTZ, $\mathrm{K}$. The use of a geographic information systen in an epidemiological study of pseudorabies (Aujeszky's disease) in Minnesota swine herds. Preventive Medicine Veterinary, v. 11, n. 3, p. 249-254, 1991.

MARTELLI, P. Strategie di controllo della malattia di Aujeszky. Rivista di Suinicoltura, v. 37, n. 2, p. 48-54, 1996.

MOTOVSKY, A.; PEEV, J. Participation of Aujeszky's disease (AD) virus in reproductive disordes in swine. In: CONGRESS INTERNATIONAL PIG VETERINARY SOCIETY, 12., 1992, Holanda. Proceeding... p. 88.

NORMAN, H. S. et al. Spatial and temporal epidemiology of pseudorabies virus infection. American Journal of Veterinary Research, v. 57, n. 11, p. 1563-1568, 1996.

OSÓRIO, F. A.; HOGG, A.; ROCK, D. L. Um entrave no controle da Doença de Aujeszky: Ocorrência de reatores sorológicos únicos em rebanhos soro-negativos. In: CONGRESSO BRASILEIRO DE VETERINÁRIOS ESPECIALISTAS EM SUÍNOS, 4 ., 1989, Itapema. Proceeding... p. 53.
PEETZ, V. S. et al. Cadeia produtiva da carne suína no Estado de São Paulo. São Paulo. 1996. 57 p. Mimeografado.

REIS, R.; REIS, F. T. Doença de Aujeszky: uma análise da situação brasileira. In: CONGRESSO BRASILEIRO DE VETERINÁRIOS ESPECIALISTAS EM SUÍNOS, 7., 1995, São Paulo. Proceeding... São Paulo: Abraves, 1995. p. 16-22.

REIS, R.; REIS, F. T. Riscos sanitários na importação de material genético de suínos. Hora Veterinária, v. 16, n. 96, p. 42-47, 1997.

ROMERO, C. H. Avanços_na pesquisas sobre o vírus da doença de Aujeszky. In: CONGRESSO LATINO DE VETERINÁRIOS ESPECIALISTAS EM SUÍNOS, 1., 1985, Rio de Janeiro. Proceeding... Rio de Janeiro: EMBRAPA, CNPSA, 1985. p. 2327.

ROMERO, C. H. et al. Monitoramento sorológico para controle da doença de Aujeszky do rebanho reprodutor suíno no Estado de Santa Catarina em 1986. Circular Técnica, n. 9, 1987. 8 p. CNPSA-EMBRAPA.

ROMERO, C. H. et al. Distribuição e prevalência de anticorpos precipitantes para o vírus da doença de Aujeszky, em plantéis suínos no Estado de Santa Catarina. Pesquisa Veterinária Brasileira, v. 4, n. 4, p. 123-127, 1984.

SMET, K. DE.; MÜELENAERE, C. DE.; PENSAERT, M. Epizootiologische situatie en toekomstige bestrijding van de ziekte van Aujeszky in Belgie en andere E. G.-Lidestaten. Vlaams Diergeneeskundig Tijdschrift, v. 58, n. 5, p. 147$154,1989$.

SOBESTIANSKY, J. Doença de Aujeszky: diagnóstico e controle. Revista Sanidade, p. 22-35, 1985.

SOBESTIANSKY, J. et al. Patologia e Clínica Suína. In: SOBESTIANSKY, J.; BARCELLOS, D. E. S. N.; MORES, N.; OLIVEIRA, S. J. (Ed.) Doença de Aujeszky. Lageado: Cometa, 1993. p. 80-87.

ZIMMER, T. K.; ZIMMERMANN, R. G. Todesurachen bei Schweinen. Prakt Tierarztl: College Veterinarmed., v. 78, n. 9,p. 772-780, 1997. 